Sharif University of Technology
Scientia Iranica
SCIENTIA
IRAN I CA
http://scientiairanica.sharif.edu

Research Note

\title{
Optimization actions for irrigation by the Howell-Bunger valves
}

\section{Ş. Yurdagül Kumcu*}

Faculty of Engineering and Architecture, Necmettin Erbakan University, Dere Asiklar/Meram District, Demec St. 42/A, Zip code: 42140, Room no: 538, Konya, Turkey.

Received 7 September 2015; received in revised form 1 May 2016; accepted 30 October 2017

\section{KEYWORDS}

Bahçelik dam; Howell-Bunger valves;

Optimum valve operating systems;

Bottom outlet;

Free discharge valves.

\begin{abstract}
In Bahçelik Dam, irrigation and drinking water is discharged from the bottom outlet to diversion channel when the reservoir water surface elevation is between $1472 \mathrm{~m}$ and $1500 \mathrm{~m}$. It was planned that the flow discharge would be automatically controlled by the valves depending on the water demand. In this system, the valve type is characterized by opening, closing, and regulating times of the valves for controlling system placed downstream of the main diversion channel. Howell-Bunger valves, which are cavitation and water hammer resistant, velocity limitless, and electronically controllable water control systems, were selected. In the experimental study, 4 Howell-Bunger valves each having $D=1400 \mathrm{~mm}$ and maximum discharge capacity $Q=8.5 \mathrm{~m}^{3} / \mathrm{s}$ were placed at the upstream part of the main diversion channel and tested in various valve openings to obtain optimum operating conditions for all reservoir water levels in a $1 / 10$ scaled model. It was found that as the reservoir elevation got higher, valve performance increased by up to $75 \%$ of valve opening. The expected discharge capacity of a valve, which worked in $100 \%$ open condition, was $8.5 \mathrm{~m}^{3} / \mathrm{s}$; however, this value was reached with two valves that worked in $100 \%$ opening at the minimum reservoir operation level, i.e. $H=1472 \mathrm{~m}$.

(C) 2018 Sharif University of Technology. All rights reserved.
\end{abstract}

\section{Introduction}

Valves used in floodgate applications have different design requirements and are usually located at the base of dams [1]. Howell-Bunger valves are used to pass a controlled amount of water downstream with no damage to the immediate environment [2]. They are ideally suited for power projects, flood control structures, and irrigation facilities as well as to drain reservoirs or ponds. Water with low dissolved oxygen content, a characteristic of discharges from impoundments, can be aerated very effectively when discharged into the atmosphere through Howell-Bunger Valves. Howell-Bunger (Fixed Cone) valves are largely used

\footnotetext{
*.E-mail address: yurdagulkumcu@gmail.com
}

in applications requiring control of water under free discharge (into the atmosphere). This kind of valves is lower in cost than any other type of free-discharge valves [3]. The Howell-Bunger valves control and dissipate enormous amounts of energy by breaking up the discharge water into a large, hollow, expanding jet [4]. They are presently being used as relief valves on hydraulic turbines and designed to operate at any position between fully open and fully closed without injurious vibration [5].

The main purpose of the Bahçelik Dam is storing the water for irrigation, supplying drinking water, producing hydroelectric power, and controlling the flood. The demand for irrigation and drinking water is supplied from the bottom outlet of the Bahçelik Dam. The maximum and the minimum reservoir levels are $H_{\max }=1500 \mathrm{~m}$ and $H_{\min }=1472 \mathrm{~m}$, respectively. The amount of flow diverted from the bottom outlet 
to the main diversion channel is regulated by HowellBunger valves controlled by the upstream water level measurements along the main diversion channel. When the amount of water demand is increasing, the released flow discharge will also be increased and, vice versa, if the amount of water demand is decreasing, the released flow discharge will also be decreased. The maximum and minimum water levels at the water level measurement section along the main diversion channel are $1471.61 \mathrm{~m}$ and $1471.21 \mathrm{~m}$, respectively. The maximum and the minimum values are very close to each other and this will result in very rapid change in valve opening range; thus, there will be some difficulties during the operational duration $[6,7]$.

In this study, a valve with very low variance in valve opening, closing, and regulating times had to be selected; also, the diameter of the valve had to be in the required range and it had to be durable for high flow resistance. There was no restriction or limitation on the flow velocity. With regards to all the above-mentioned limitations, the Howell-Bunger valves were preferred for the project. In the laboratory, the performance of the Howell-Bunger valves was experimentally tested with physical model studies. In the experimental study, the conveying conduit transmitting flow from bottom outlet to the valves had maximum flow discharge capacity, $Q=34 \mathrm{~m}^{3} / \mathrm{s}$, and the diameter $D=2400 \mathrm{~mm}$. Flow was diverted from conveying conduit to main diversion channel by 4 branches all controlled by Howell-Bunger valves, each having $D=$ $1400 \mathrm{~mm}$ and discharge capacity $Q=8.5 \mathrm{~m}^{3} / \mathrm{s}$, placed at the upstream part of the main diversion channel. They were tested in various valve openings to obtain optimum operating conditions for all reservoir water levels during the operating of the dam in a $1 / 10$ scaled model.

The Howell- Bunger valve was basically a cylinder gate mounted with the axis in horizontal direction. A conical end piece with upstream apex was connected to the valve body vanes. A movable external horizontal sleeve controlled the discharge by varying the opening between the sleeve and the cone. The discharge was in the form of a diverging hollow conical jet. Because of this characteristic, the valve best adapted to conditions where the confinement of the jet and excessive spray were not important considerations.

The principles of the operational systems for the Howell-Bunger valves used in the experimental study and model set up are shown in Figures 1 and 2, respectively.

\section{Experimental arrangement}

Physical model studies were conducted in a 1/10 scaled physical model in two stages; first, upstream flow conditions were tested and modified to obtain uniform

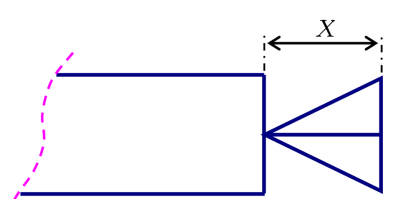

Full opening, $X=0,70 \mathrm{~m}$

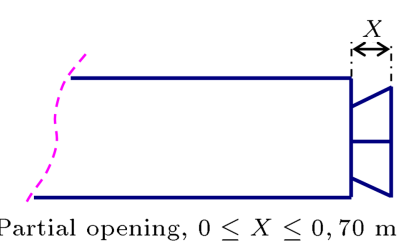

Partial opening, $0 \leq X \leq 0,70 \mathrm{~m}$
Figure 1. Operational and opening principles of the Howell-Bunger valves.

and non-wavy smooth flow surface conditions as the valve operation depended on the water surface level reading, which was measured with a device placed along the main channel. Then, performance of the valves with all possible flow conditions as well as all reservoir operating conditions was tested for different operational conditions and valve openings. As a result, the major modifications were made in the original project design plan. Plan view and the photos of the original project of the Bahçelik Dam Bottom Outlet constructed in the Hydraulic Model Laboratory in State Hydraulic Works of Turkey (DSI) are shown in Figures 3 and 4, respectively.

\section{Discussion of results}

\subsection{Flow conditions between values and the water level measurement chamber}

Valve opening was controlled by the water surface level measured at the measurement station downstream of the main diversion channel. After the original project was constructed in the laboratory, a series of experiments were conducted in order to investigate the flow characteristics through the bottom outlet to the main diversion channel. Based on the test results, to provide the uniform flow conditions, the following modifications were done:

1. In the original project, 4 valves were surrounded by 4 steel galleries (like cylindrical hollows) each having the diameter $D=3500 \mathrm{~mm}$. The aim of each gallery was to prevent excessive spraying of the water jet trajectory issuing from the HowellBunger valves. Experimental observations showed that the lengths of the galleries were unnecessarily high and they worked ineffectively in reducing water jet energy. To solve this problem, after a series of tests, the lengths of the galleries were reduced from $10 \mathrm{~m}$ to $5.5 \mathrm{~m}$;

2. The lengths of the separating walls placed between the valves were reduced corresponding to the lengths of the galleries;

3. The bridge planned for using a service road and an energy dissipator were routed in the downstream direction;

4. New stilling pool was designed to increase energy dissipation rate. The depth of the channel was 

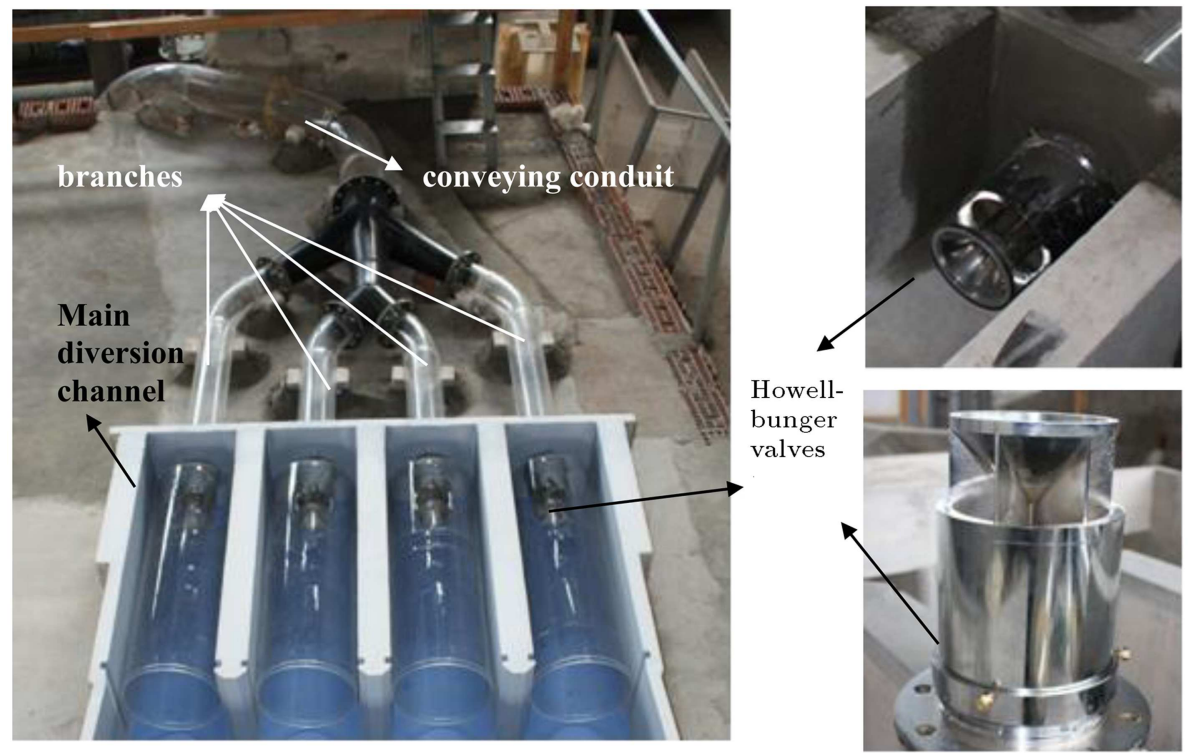

Figure 2. Model set-up and details of the Howell-Bunger valves.

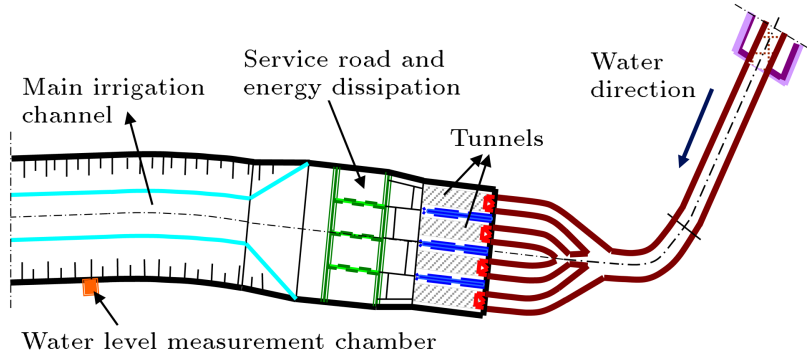

Figure 3. Original project design of the Bahçelik Dam Bottom Outlet.
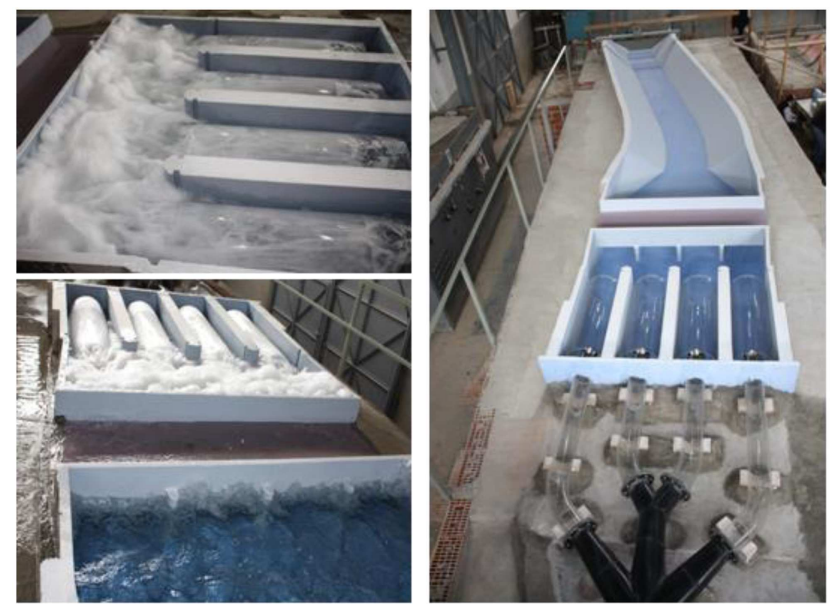

Figure 4. Views from the physical model of the original project.

deepened by $1 \mathrm{~m}$ between the galleries and the bridge which was to be used for service road and energy dissipation as $1 / 3$ of it was submerged;

5. Because the energy dissipator was insufficient and could not meet the desired energy dissipation rate,

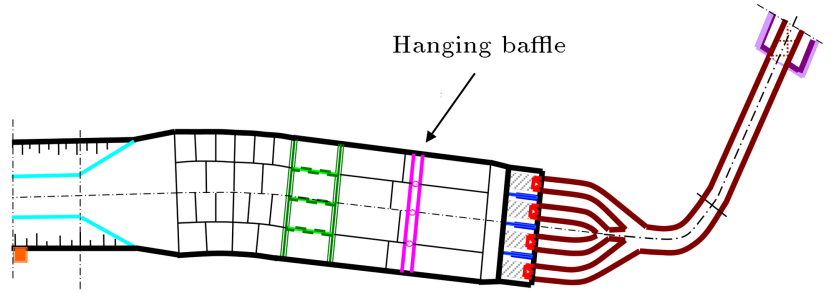

Figure 5. Final project design obtained from the experimental study of the Bahçelik Dam Bottom Outlet.

an additional hanging baffle type energy dissipater was planned, designed, and added to the position between the galleries and the stilling pool;

6. The heights of the side walls were increased in case of high water levels through the channels;

7. Water level measurement chamber was moved downstream of the main diversion channel.

Figure 5 shows a definition sketch of the final project attained with the experimental study; also, the general view of the channel and the flow through the main diversion channel are shown in Figure 6.

\subsection{Valve operation system and performance of the valves}

During the operation stage of the bottom outlet, the number and the opening rates of the valves would be recognized by the water demand. In the laboratory study, downstream of the main diversion channel, minimum water surface level was kept constant at $H=1471.21 \mathrm{~m}$ as the maximum water demand was at this stage. The number of the valves and the valve opening rates were systematically investigated for each reservoir operation condition. At first, reservoir water surface level was fixed at $H_{\max }=1500 \mathrm{~m}$. While this 

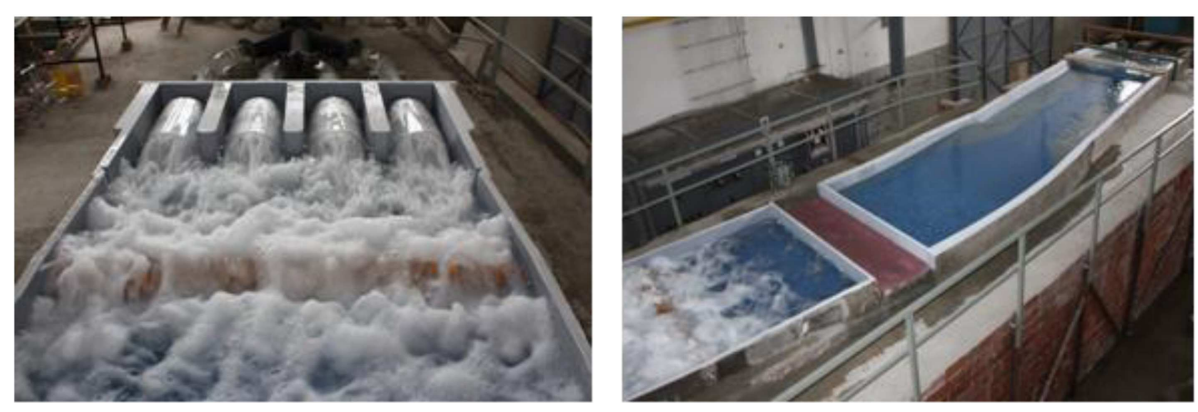

Figure 6. Views from the physical model of the final project.

value was kept constant, the discharge varied from the maximum water demand $Q=34 \mathrm{~m}^{3} / \mathrm{s}$ to $Q=1 \mathrm{~m}^{3} / \mathrm{s}$ by lowering discharge by $1 \mathrm{~m}^{3} / \mathrm{s}$ after each conducted experiment. Afterwards, this procedure was repeated for each reservoir surface level up to $H_{\min }=1472 \mathrm{~m}$, by decreasing the water level by $1 \mathrm{~m}$ after each tested reservoir water level.

After arranging the water levels for both the reservoir and the downstream channel, the valve opening ranges were investigated for each flow discharges. A valve was used only up to $Q=8.5 \mathrm{~m}^{3} / \mathrm{s}$ and if the flow discharge exceeded $Q=8.5 \mathrm{~m}^{3} / \mathrm{s}$, the valve opening range was kept constant and the second valve was taken into operation. Similarly, all the experiments related to the rest of the valves were repeated. As soon as the discharge was higher than $17 \mathrm{~m}^{3} / \mathrm{s}$, the opening range of the two valves was kept constant and the third valve was taken into operation. Finally, if the discharge value exceeded $Q=25.5 \mathrm{~m}^{3} / \mathrm{s}$, the opening range of the three valves was kept constant and the last valve undertook operation. Operational conditions of the Howell-Bunger valves for various flow conditions are given in Table 1.

The flow was divided into 4 branches between the bottom outlet and the main diversion channel by secondary pipe branches. It can be concluded from the experimental study that, if there are multiple valves in operation, although the valve opening ranges are the same, the discharges of all valves show different scenarios. Such flow conditions probably result from flow separation and complex flow conditions [8]. After the laboratory experience, during the reservoir operation, valve opening ranges were arranged in a way that all valves had the same discharge capacity

Table 1. Experimental data for various $L_{a}$ and $Q$ values tested $\left(B_{c}=0.10 \mathrm{~m}\right.$ and $\left.Z_{c} / y=(-) 0.50\right)$.

\begin{tabular}{|c|c|c|c|c|c|c|c|c|c|c|c|c|}
\hline $\begin{array}{c}L_{a}{ }^{a} \\
(\mathrm{~cm})\end{array}$ & $\begin{array}{c}Q^{\mathrm{b}} \\
(1 / \mathrm{s})\end{array}$ & $U / U_{c}$ & $\begin{array}{c}y^{\mathrm{c}} \\
(\mathrm{cm})\end{array}$ & Fr & $\begin{array}{c}\left(d_{s}\right)_{\max _{c}}{ }^{\mathrm{d}} \\
(\mathrm{cm})\end{array}$ & $\begin{array}{c}\left(d_{s}\right)_{\max }{ }^{\mathrm{e}} \\
(\mathrm{cm})\end{array}$ & $\begin{array}{c}\left(d_{s}\right)_{a_{c}}{ }^{\mathrm{f}} \\
(\mathrm{cm})\end{array}$ & $\begin{array}{c}Z \\
(\mathrm{~cm}) \\
\end{array}$ & $\begin{array}{c}X \\
(\mathrm{~cm}) \\
\end{array}$ & $\begin{array}{c}\xi \\
\left({ }^{\circ}\right)\end{array}$ & $\begin{array}{c}L \\
(\mathrm{~cm}) \\
\end{array}$ & $L / L_{a}$ \\
\hline 15 & 35 & 0.86 & 6.45 & 0.57 & 5 & 15.5 & 9.4 & 29.6 & 11 & 20.4 & 31.57 & 2.10 \\
\hline 15 & 40 & 0.88 & 7.15 & 0.53 & 5 & 16.1 & 10.2 & 30.5 & 12.5 & 22.3 & 32.96 & 2.19 \\
\hline 15 & 45 & 0.89 & 7.95 & 0.48 & 5 & 15.4 & 8.6 & 30 & 15.5 & 27.3 & 33.76 & 2.25 \\
\hline 15 & 50 & 0.90 & 8.85 & 0.43 & 5 & 15.7 & 9 & 31 & 16 & 27.3 & 34.88 & 2.32 \\
\hline 15 & 55 & 0.91 & 9.60 & 0.41 & 5 & 16.1 & 11.1 & 31.5 & 11.5 & 20.7 & 33.53 & 2.23 \\
\hline 20 & 35 & 0.86 & 6.45 & 0.57 & 5 & 17.5 & 13 & 33.5 & 20 & 30.8 & 39.01 & 1.95 \\
\hline 20 & 40 & 0.88 & 7.15 & 0.53 & 5 & 17.5 & 13.5 & 33 & 21 & 32.5 & 39.11 & 1.95 \\
\hline 20 & 45 & 0.89 & 7.95 & 0.48 & 5 & 18 & 13.5 & 36.5 & 19.5 & 28.1 & 41.38 & 2.07 \\
\hline 20 & 50 & 0.90 & 8.85 & 0.43 & 5 & 18.2 & 13 & 35 & 22 & 32.1 & 41.34 & 2.07 \\
\hline 20 & 55 & 0.91 & 9.60 & 0.41 & 5 & 18.6 & 13.4 & 35 & 21.6 & 31.7 & 41.13 & 2.05 \\
\hline 25 & 35 & 0.86 & 6.45 & 0.57 & 5 & 18.1 & 15.1 & 44 & 30 & 34.3 & 53.25 & 2.13 \\
\hline 25 & 40 & 0.88 & 7.15 & 0.53 & 5 & 19.4 & 15.5 & 48 & 31 & 32.8 & 57.14 & 2.28 \\
\hline 25 & 45 & 0.89 & 7.95 & 0.48 & 5 & 20.3 & 15.8 & 46.5 & 36.2 & 37.0 & 58.92 & 2.35 \\
\hline 25 & 50 & 0.90 & 8.85 & 0.43 & 5 & 20.6 & 14.7 & 46.5 & 41 & 41.4 & 61.99 & 2.47 \\
\hline 25 & 55 & 0.91 & 9.60 & 0.41 & 5 & 21.5 & 13.2 & 48.5 & 47 & 44.1 & 67.53 & 2.70 \\
\hline
\end{tabular}

${ }^{\mathrm{a}} L_{a}$ : abutment length; ${ }^{\mathrm{b}} Q$ : discharge; ${ }^{\mathrm{c}} y$ : depth of flow; ${ }^{\mathrm{d}}\left(d_{s}\right) \max _{c}$ : depth of scour with collar;

${ }^{\mathrm{e}}\left(d_{s}\right)_{\text {max }}$ : depth of scour without collar; ${ }^{\mathrm{f}}\left(d_{s}\right) a_{c}$ : depth of scour away from abutment with collar. 


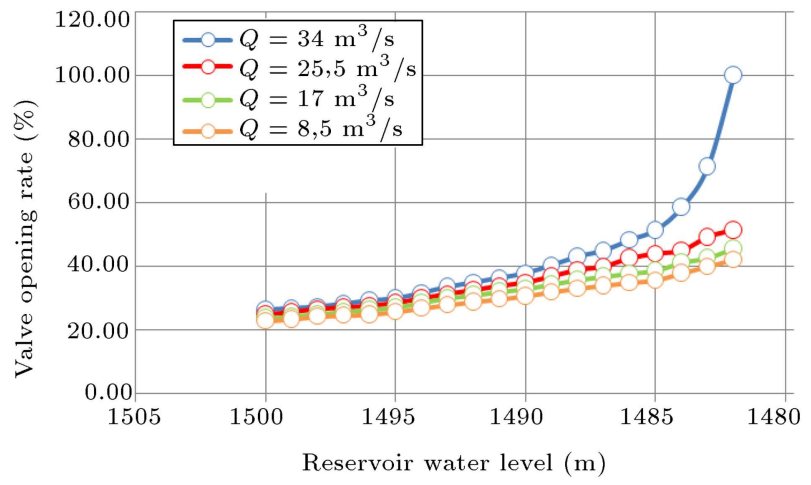

Figure 7. Variations of valve opening rates with various reservoir water levels.

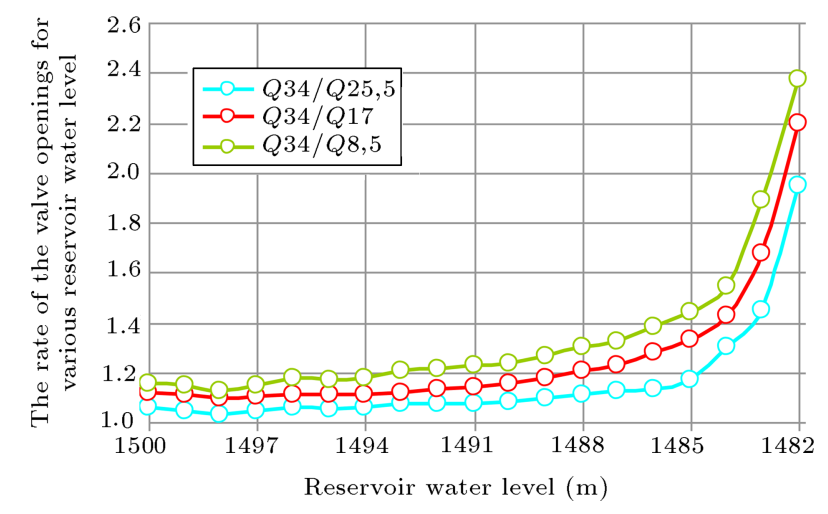

Figure 8. Effect of water demand on the valve opening rate.

for a given valve opening range. This optimization helped to simplify programming as well as operating the automatic control system [9-11].

In addition, as all valves released the same amount of water, the uniform flow condition along the channel was reached in a short time.

Figure 7 is plotted to determine the optimum valve opening range for known value of reservoir water level. Referring to this figure, one can conclude that valve opening rate increases when reservoir water level decreases for a given discharge. It also increases with increase in water demand for a constant reservoir water level.

Figure 8 shows the effect of water demand on the valve opening rate. In this figure, it is clearly seen that when reservoir water level decreases, as water pressure decreases, the performance of the valves is weakened; thus, the rate of valve opening rises for a given discharge. It can be concluded that the valves loose their efficiency with increase in the discharges for a given reservoir water level. In fact, if $Q=8.5 \mathrm{~m}^{3} / \mathrm{s}$ is observed by $22.9 \%$ valve opening rate, it is expected that $Q=34 \mathrm{~m}^{3} / \mathrm{s}$ can be observed for all the 4 valves with the same opening rate of $22.9 \%$. However, it is clear from this figure that $Q=34 \mathrm{~m}^{3} / \mathrm{s}$ can be obtained when the opening rate of the valves is 2.4 times higher than the observed one when $Q=8.5 \mathrm{~m}^{3} / \mathrm{s}$.

Table 2 lists the experimental data for reservoir water level of $H=1483 \mathrm{~m}$ to show water demand efficiency with an example.

It is seen from the experimental results that in any case of operation, at least one valve should be opened for all water demands. Therefore, Figure 9 is drawn to show the effect of the reservoir water level on the valve opening rate. As the water demand increases, the valves get involved in operating system one by one and start influencing the efficiency of the previous valves that are under operation. It is clear from Figure 9 that when the reservoir water level decreases, valve opening rate shows an increasing trend for a given discharge.

\subsection{Variation of rating curves depending on the valve position}

Flow conditions may show different characteristics at the upstream face of each valve as the flow is divided into 4 branches after the main diversion pipe. In order to see if the valve operating conditions show discrepancies or not, considering the system to be symmetrical, 2 piezometer reading points were determined; one was placed in the internal and the other one was placed in the external pipe of the network system. During each measurement, only the chosen valve was tested and the others were kept closed; the flow rates were measured by increasing the pressure level one by one meter for the opening rates of $25 \%, 50 \%, 75 \%$, and full openness.

Pressure reading points and measurements made at points 1 and 2 with respect to valve opening rates are both shown in Figure 10.

As can be seen from Figure 11, the discharge obtained for the valves increases with increase in the water level. The higher water depth for a constant valve opening leads to higher discharge capacity of the valves. If the valve opening increases for a given water depth, the discharge capacity of the valves also increases.

This increase can clearly be seen when the valve opening changes from $25 \%$ to $75 \%$. However, the flow discharge does not show any change if the valve opening is higher than $75 \%$.

\section{Conclusions}

In this study, flow characteristics between the main diversion channel and bottom outlet of the Bahçelik Dam were experimentally investigated. There were a series of experiments in the hydraulics laboratory to point out the efficiencies and to optimize the operation programme for remote control system of the HowellBunger valves.

It was observed that the uniform flow conditions 
Table 2. Discharge-valve opening variation for the reservoir level of $H=1483 \mathrm{~m}$.

\begin{tabular}{|c|c|c|c|c|c|c|c|c|}
\hline \multirow[t]{2}{*}{$Q\left(\mathrm{~m}^{3} / \mathrm{s}\right)$} & \multicolumn{4}{|c|}{ Valve opening $(\mathrm{cm})$} & \multicolumn{4}{|c|}{ Valve opening (\%) } \\
\hline & 1. Valve & 2. Valve & 3. Valve & 4. Valve & 1. Valve & 2. Valve & 3. Valve & 4. Valve \\
\hline 1 & 2.40 & Closed & Closed & Closed & 3.4 & Closed & Closed & Closed \\
\hline 2 & 5.80 & Closed & Closed & Closed & 8.3 & Closed & Closed & Closed \\
\hline 3 & 8.20 & Closed & Closed & Closed & 11.7 & Closed & Closed & Closed \\
\hline 4 & 11.60 & Closed & Closed & Closed & 16.6 & Closed & Closed & Closed \\
\hline 5 & 15.00 & Closed & Closed & Closed & 21.4 & Closed & Closed & Closed \\
\hline 6 & 18.00 & Closed & Closed & Closed & 25.7 & Closed & Closed & Closed \\
\hline 7 & 22.00 & Closed & Closed & Closed & 31.4 & Closed & Closed & Closed \\
\hline 8.5 & 28.00 & Closed & Closed & Closed & 40.0 & Closed & Closed & Closed \\
\hline 9 & 28.00 & 1.90 & Closed & Closed & 40.0 & 2.7 & Closed & Closed \\
\hline 10 & 28.00 & 4.00 & Closed & Closed & 40.0 & 5.7 & Closed & Closed \\
\hline 11 & 28.00 & 7.30 & Closed & Closed & 40.0 & 10.4 & Closed & Closed \\
\hline 12 & 28.00 & 10.50 & Closed & Closed & 40.0 & 15.0 & Closed & Closed \\
\hline 13 & 28.00 & 14.00 & Closed & Closed & 40.0 & 20.0 & Closed & Closed \\
\hline 14 & 28.00 & 17.30 & Closed & Closed & 40.0 & 24.7 & Closed & Closed \\
\hline 15 & 28.00 & 22.50 & Closed & Closed & 40.0 & 32.1 & Closed & Closed \\
\hline 16 & 28.00 & 26.00 & Closed & Closed & 40.0 & 37.1 & Closed & Closed \\
\hline 17 & 29.80 & 29.80 & Closed & Closed & 42.6 & 42.6 & Closed & Closed \\
\hline 18 & 29.80 & 29.80 & 2.80 & Closed & 42.6 & 42.6 & 4.0 & Closed \\
\hline 19 & 29.80 & 29.80 & 6.30 & Closed & 42.6 & 42.6 & 9.0 & Closed \\
\hline 20 & 29.80 & 29.80 & 10.00 & Closed & 42.6 & 42.6 & 14.3 & Closed \\
\hline 21 & 29.80 & 29.80 & 13.80 & Closed & 42.6 & 42.6 & 19.7 & Closed \\
\hline 22 & 29.80 & 29.80 & 18.00 & Closed & 42.6 & 42.6 & 25.7 & Closed \\
\hline 23 & 29.80 & 29.80 & 23.50 & Closed & 42.6 & 42.6 & 33.6 & Closed \\
\hline 24 & 29.80 & 29.80 & 27.60 & Closed & 42.6 & 42.6 & 39.4 & Closed \\
\hline 25.5 & 34.50 & 34.50 & 34.50 & Closed & 49.3 & 49.3 & 49.3 & Closed \\
\hline 26 & 34.50 & 34.50 & 34.50 & 1.90 & 49.3 & 49.3 & 49.3 & 2.7 \\
\hline 27 & 34.50 & 34.50 & 34.50 & 5.80 & 49.3 & 49.3 & 49.3 & 8.3 \\
\hline 28 & 34.50 & 34.50 & 34.50 & 10.30 & 49.3 & 49.3 & 49.3 & 14.7 \\
\hline 29 & 34.50 & 34.50 & 34.50 & 16.00 & 49.3 & 49.3 & 49.3 & 22.9 \\
\hline 30 & 34.50 & 34.50 & 34.50 & 22.00 & 49.3 & 49.3 & 49.3 & 31.4 \\
\hline 31 & 34.50 & 34.50 & 34.50 & 28.00 & 49.3 & 49.3 & 49.3 & 40.0 \\
\hline 32 & 36.80 & 36.80 & 36.80 & 36.80 & 52.6 & 52.6 & 52.6 & 52.6 \\
\hline 33 & 46.00 & 46.00 & 46.00 & 46.00 & 65.7 & 65.7 & 65.7 & 65.7 \\
\hline 34 & 50.00 & 50.00 & 50.00 & 50.00 & 71.4 & 71.4 & 71.4 & 71.4 \\
\hline
\end{tabular}

could not be obtained with the original project design. Even in high discharges, no absolute water depths were recorded at the water measurement chamber because of the waves. Therefore, there were some modifications to the original project for the purpose of higher energy dissipation to obtain uniform flow conditions before the water level measurement section.
With the system configuration given in this study, efficiency of a single valve is higher than that of a group of valves for a given valve opening at constant reservoir water level. However, during the multiple valve operation conditions, performance losses of Howell-Bunger valves must be taken into consideration, especially in higher water demands. 


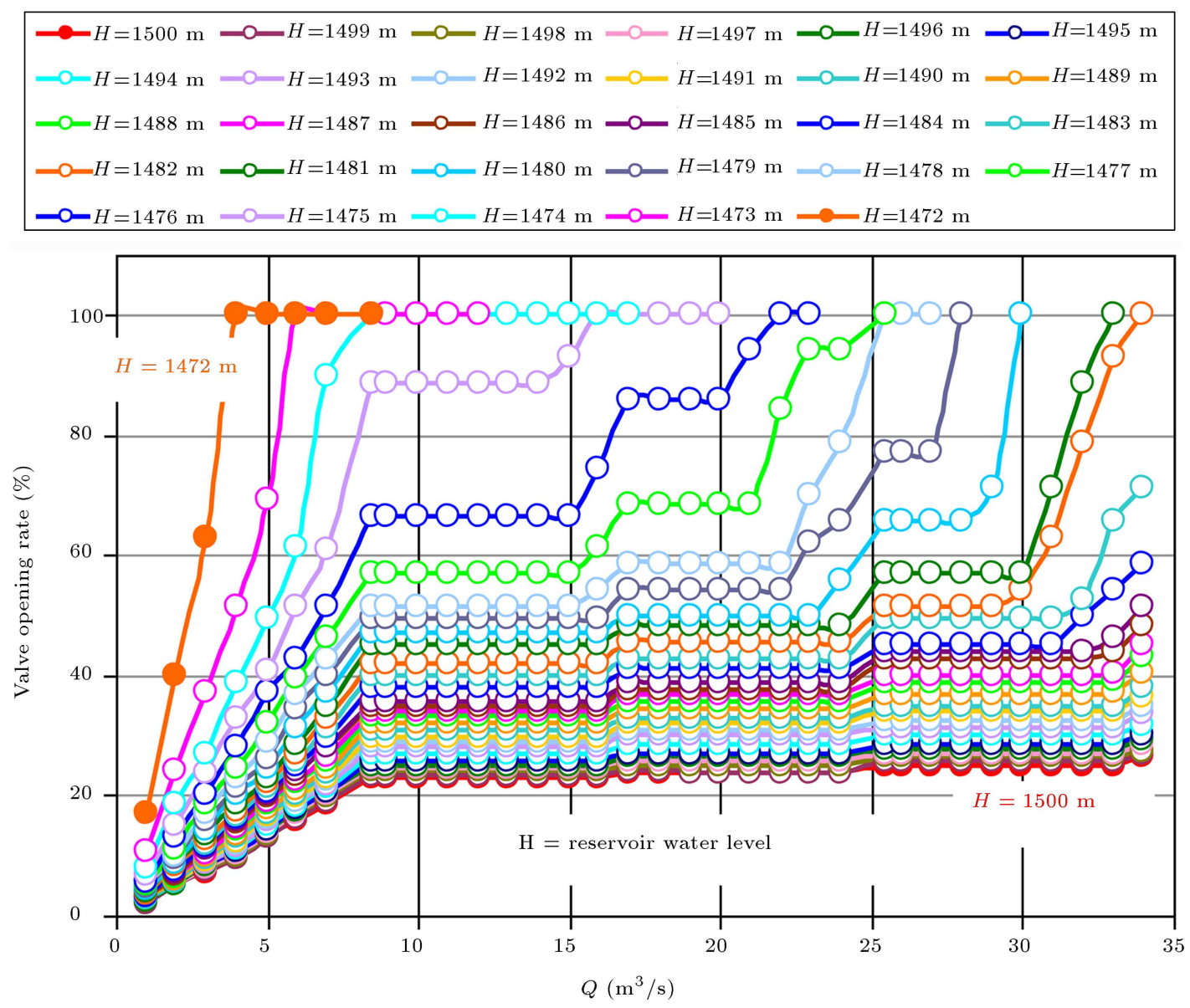

Figure 9. Effect of reservoir water level on the valve opening rate for a single valve under operation for various (from minimum to maximum) water demand.

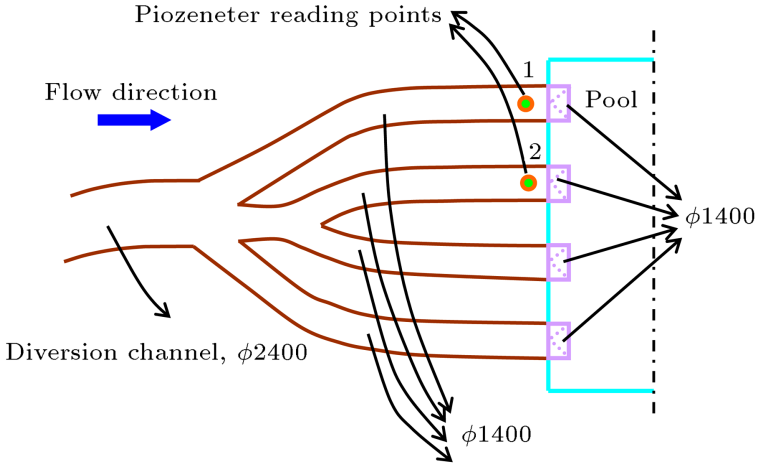

Figure 10. Pressure reading points.

Valve performance increases up to $75 \%$ of the valve opening when the reservoir elevation gets higher. Although the expected discharge capacity of a valve that woks in $100 \%$ open condition is $8.5 \mathrm{~m}^{3} / \mathrm{s}$, this value is reached with two valves working in $100 \%$ performance at the minimum reservoir operation level, i.e. $H=1472 \mathrm{~m}$. The discharge value $Q=17 \mathrm{~m}^{3} / \mathrm{s}$ $\left(2^{*} 8,5 \mathrm{~m}^{3} / \mathrm{s}\right)$ is expected to be obtained by two valves under operation; however, it can also be reached by

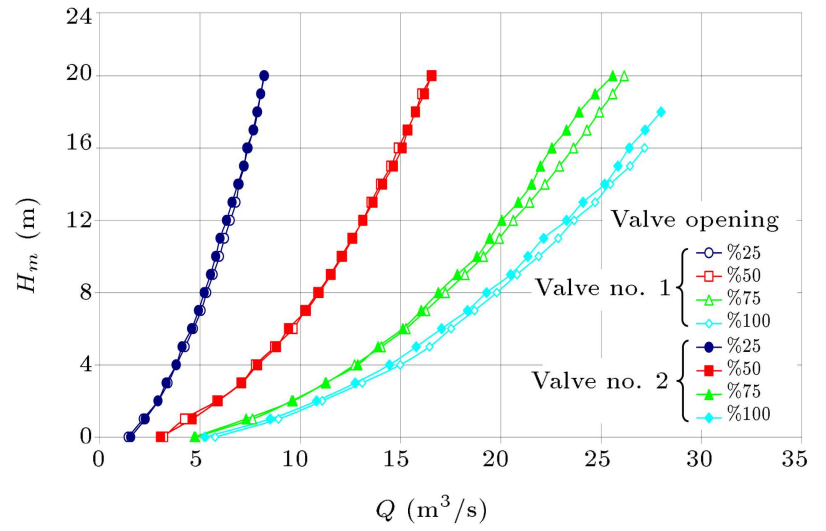

Figure 11. Rating curves of valves.

4 valves, 3 with $100 \%$ opening and the last one with $71,4 \%$ opening, for $H=1472 \mathrm{~m}$.

\section{References}

1. "Energy dissipators", IAHR Hydraulic Structures Design Manual., A.A. Balkema, Rotterdam (1995).

2. Özcan, M. and ve Özkan, A.O. PLC Applications in 
Automation Systems [Otomasyon Sistemlerinde PLC Uygulamaları], Atlas Press, İstanbul (2004).

3. http://www.vortexhydradams.com/Products/BigSize Valves/HowellBungerfixedcone/tabid/71/language/enUS/Default.aspx

4. Vischer, D.L. and Hager, W.H., In Dam Hydraulics, J. Wiley \& Sons Ltd., England (1997).

5. http://www.rodneyhunt.com/Fixed_Cone_Valves.pdf

6. Kavurmacıoğlu, L. "Water hammer in pipelines and measurements techniques of water hammer" [Boru hatlarında su darbesi hatlarında su darbesi olayı ve Önlemeçareleri], IX. National Montage Engineering Congress Ankara, (2009).

7. Design of Small Dams, Bureau of Reclamation, Washington, USA (1974).

8. Şentürk, F., Hydraulic Principles of Dam Engineering [Barajların Projelendirilmesinde Hidrolik Esaslar DSİ Matbaas], Press: 1, Ankara (1988).

9. Ball, J.W. and Hebert, D.J. "The development of high-head outlet valves", Hydraulic Laboratory Report Hyd. 240, Bureau of Reclamation, Denver, Colorado (1948).
10. Kumcu, Ş.Y. Hydraulic Model Report of Bottom Outlet Structure of Bahçelik Dam [Bahçelik Barajı Dipsavak Su Alma Yapısı hidrolik çalışmaları model raporu], DSI Press, HI-1001, Ankara (2009).

11. Vennard, J.K. and Street, R.L., In Elementary Fluid Mechanics, J. Wiley \& Sons Ltd., Canada (1982).

\section{Biography}

Şerife Yurdagül Kumcu graduated in 1992 from Selcuk University of Konya, Turkey. She worked on labyrinth spillways and scour measurements around the bridge abutments during the MSc and $\mathrm{PhD}$ studies, respectively, at Middle East Technical University (METU). Then, she worked for the State Hydraulic Works as a research engineer in the Hydraulic Laboratory of the Technical Research and Quality Control Department. Currently, she is working in Hydraulic Department at Necmettin Erbakan University and performing a comparative study on flood control and management as well as sedimentation problems using the NCCHE computer model and physical scale models. 